\title{
An improvement on the dust emission scheme in the global aerosol-climate model ECHAM5-HAM
}

\author{
T. Cheng ${ }^{1,3}$, Y. Peng ${ }^{1,4}$, J. Feichter ${ }^{1}$, and I. Tegen ${ }^{2}$ \\ ${ }^{1}$ Max-Planck-Institute for Meteorology, Bundesstr. 53, 20146, Hamburg, Germany \\ ${ }^{2}$ Leibniz-Institute for Tropospheric Research, Permoserstrasse 15, 04318 Leipzig, Germany \\ ${ }^{3}$ Department of Environmental Science and Engineering, Fudan University, Shanghai, 200433, China \\ ${ }^{4}$ Canadian Centre for Climate Modeling and Analysis, 3964 Gordon Head Road, Victoria, B.C., V8N 3X3, Canada
}

Received: 30 August 2007 - Published in Atmos. Chem. Phys. Discuss.: 27 September 2007

Revised: 3 January 2008 - Accepted: 31 January 2008 - Published: 28 February 2008

\begin{abstract}
Formulation of the dust emission scheme in the global aerosol-climate modeling system ECHAM5-HAM has been improved. Modifications on the surface aerodynamic roughness length, soil moisture and East-Asian soil properties are included in the parameterization, which result in a large impact on the threshold wind friction velocity for aeolian erosion and thus influence the simulated dust emission amount. The annual global mean of dust emission in the year 2000 is reduced by $76.5 \%$ and $2.2 \%$, respectively, due to changes in the aerodynamic roughness length and the soil moisture. An inclusion of detailed East-Asian soil properties leads to an increase of $16.6 \%$ in the annual global mean of dust emission, which exhibits mainly in the arid and semiarid areas of northern China and southern Mongolia. Measurements of the surface dust concentrations are collected in remote marine sites globally and in dust source regions of East Asia. The averaged relative differences between model results and measurements are reduced from $17 \%$ to $12 \%$ in global remote marine sites and from $69 \%$ to $30 \%$ in East Asia, by including the improvements. Comparisons between model results and available measurements verify a more realistic dust distribution with the improved emission scheme.
\end{abstract}

\section{Introduction}

Atmospheric aerosol is an important forcing factor in the global climate system. However, considerable uncertainties still exist in the estimates of direct and indirect effects of aerosols on the earth radiation budget and global climate changes (IPCC, 2007). Among several atmospheric aerosol species, mineral dust is one of the largest contributors to the global aerosol loading and has strong impacts on regional and global climates (Tegen et al., 1996), marine and terrestrial ecosystems (Martin et al., 1988; Chadwick et al., 1999), as well as the long-term climate trends (Petit et al., 1990, 1999).

A global aerosol-climate model can help to understand the complex aerosol cycle for past, present and future conditions, to distinguish natural from anthropogenic aerosol sources and to identify the effect of specific aerosol components on the global climate system. The global simulation of dust cycle is able to depict the dust emission, transport and deposition on a large scale (e.g., Tegen et al., 2002; Luo et al., 2003). However, global model predicted dust concentrations and distributions are still quite uncertain, especially perform poorly in Asia (Kinne et al., 2006). The dust relevant processes are rather simplified when parameterized in global models. The lack of observational data on a large scale makes it difficult to evaluate on climate model results.

The aerosol-climate modeling system ECHAM5-HAM predicts the ensemble of micro-physically interacting internally-mixed and externally-mixed aerosol populations as well as their size distribution and composition (Stier et al., 2005). The model can appropriately estimate the global distribution, transportation and climate impact of dust aerosols. Nevertheless, the parameterization of dust emission in ECHAM5-HAM is still rather crude. Some key parameters such as the surface roughness, soil moisture and soil properties at various locations are not very well included. Therefore further modifications on the dust emission scheme are expected in order to simulate the mineral dust aerosols more realistically. 
In this study, we present an improved dust emission scheme for application into the ECHAM5-HAM, which incorporates updates of the surface aerodynamic roughness length, soil moisture and East-Asian soil properties. Objectives of this work are to include a more physically-based parameterization of the threshold wind friction velocity, and to obtain a more realistic surface dust emission than previously. In Sect. 2, we describe the three modifications of the improved dust emission scheme applying into ECHAM5HAM. Results from model simulations with the improved scheme as well as comparisons with the previous simulation and measurements are shown in Sect. 3. Some discussions are presented in Sect. 4 and conclusions are given in Sect. 5.

\section{Improvement on the dust emission scheme in ECHAM5-HAM}

The dust emission driven by wind in arid and semi-arid areas is a non-linear physical process, which depends on both surface features and meteorological conditions in the potential source areas. The emission flux of moveable soil-derived particles is a power function of the wind friction velocity, and occurs only if the threshold of wind friction velocity is exceeded. The threshold value is primarily a function of the soil size distribution, the roughness of erodible surface (Marticorena and Bergametti, 1995), and the soil moisture (Fécan et al., 1999). The developed dust emission scheme and the required input parameters for a large-scale model application are already well described by Marticorena et al. (1997a).

The dust emission scheme originally implemented in ECHAM5-HAM follows Tegen et al. (2002) and results have been described in Stier et al. (2005). The emission scheme is coupled online and depends on the prognostic wind speed at 10 meter above the surface and the model predicted hydrological fields. In the original scheme, global soil textures are prescribed for preferential source regions (dried paleolake beds, Tegen et al., 2002), as well as with data given in the Food and Agriculture Organization/United Nations Educational, Scientific, and Cultural Organization (FAO/UNESCO) soil map of the World (Zobler, 1986). The emission flux is calculated from 192 internal dust size classes, which range from 0.2 to $1300 \mu \mathrm{m}$ in diameter and are grouped into three log-normal size distributions. The supercoarse mode particles are ignored in the emission calculation because they settle down very quickly due to large masses. The saltation process is parameterized as in Marticorena and Bergametti (1995). A ratio between vertical and horizontal emission fluxes is prescribed for each soil type (Tegen et al., 2002). The vertical emission fluxes are integrated over the 192 internal size classes and are summed up into the insoluble accumulation and coarse modes respectively, for the subsequent simulation of advection and deposition processes in model. The mass-median radii are of $0.37 \mu \mathrm{m}$ and $1.75 \mu \mathrm{m}$ and standard deviations are of 1.59 and 2.00 for the two dust modes respectively.

Based on the original scheme described above, some more physically-based formulation and more updated data are included in this study, in order to simulate the dust emission process more realistically. Modifications on the surface roughness length, soil moisture parameterization and soil properties in East Asia are introduced in the improved emission scheme, which are described respectively in the following subsections.

\subsection{Surface aerodynamic roughness length}

The dust emission scheme is related to a parameterization of the threshold wind friction velocity $\left(U_{t}^{*}\right)$, which is a function of the size of erodible soil particles $\left(D_{p}\right)$, the local aerodynamic roughness length of overall surface $\left(Z_{0}\right)$, and the local aerodynamic roughness length of erodible or uncovered surface $\left(z_{0 s}\right)$. In ECHAM5-HAM, the size-dependent threshold of wind friction velocity $U_{t}^{*}\left(D_{p}\right)$ is calculated following Eqs. (1) and (2) in Marticorena et al. (1997a). $U_{t}^{*}$ is also related to the roughness length as shown below:

$$
\begin{aligned}
& U_{t}^{*}\left(D_{P}, Z_{0}, z_{0 s}\right)=\frac{U_{t}^{*}\left(D_{p}\right)}{f_{\text {eff }}\left(Z_{0}, z_{0 s}\right)} \\
& f_{\text {eff }}\left(Z_{0}, z_{0 s}\right)=1-\left[\ln \left(\frac{Z_{0}}{z_{0 s}}\right) / \ln \left(0.35\left(\frac{10}{z_{0 s}}\right)^{0.8}\right)\right]
\end{aligned}
$$

Where $f_{\text {eff }}$ is the efficient friction velocity ratio defined as the ratio of local to total friction velocity on the basis of a drag partition scheme developed by Marticorena and Bergametti (1995). This parameterization was proved to agree with the wind tunnel and in-situ measurements of threshold wind friction velocities taken over a variety of natural erosion surfaces (Gillette et al., 1982; Marticorena et al., 1997a). However, the application of such a physically-based parameterization in a large scale model is limited due to the lack of global information characterizing the surface features in arid and semi-arid areas, particularly the surface aerodynamic roughness length $Z_{0}$.

The aerodynamic roughness length $Z_{0}$ is defined as the height above a surface at which the wind profile is assumed to be zero. It relates to both quantities of potentially eroded material and the minimum wind speed required for raising the dust particles (Gillette and Passi, 1988). The threshold velocity $U_{t}^{*}$ to initiate the dust emission is increased in areas with higher $Z_{0}$ compared to smooth surfaces (cf., Eqs. 1 and 2 ). The enhanced $Z_{0}$ also reduces the wind friction velocity and decreases the dust emission flux. Previous global model of dust cycle either uses a prescribed constant $Z_{0}$ field over the globe (Tegen et al., 2002), or calculates the dust emission flux directly from the model predicted surface wind speed instead of the wind friction velocity, implicitly assuming a constant $Z_{0}$ (Ginoux et al., 2001). This is because few $Z_{0}$ data is available in arid and semi-arid areas of the globe. 
Recently, Marticorena et al. (2004) mapped the surface roughness length $Z_{0}$ in North Africa based on measurements with the POLarization and Directionality of the Earth's Reflectance (POLDER) instrument on board the ADvanced Earth Observation Satellite (ADEOS) platform. The resulted $Z_{0}$ was derived from an empirical relationship between the satellite observed bidirectional reflectances and estimates of surface roughness from in-situ measurements. Following a similar method, Prigent et al. (2005) derived a global $Z_{0}$ field from observations in arid and semi-arid areas of the globe, according to measurements with the European Remote Sensing (ERS) satellite scatterometer.

In the previous dust emission scheme of ECHAM5-HAM, the aerodynamic roughness length $Z_{0}$ was fixed as a constant value equal to the smooth aerodynamic roughness length $z_{0 s}$ of $0.001 \mathrm{~cm}$. The globally constant $Z_{0}$ field is invariant to time and location, and thus does not account for the potential changes related to the vegetation cycle or anthropogenic influences. In the improved dust emission scheme, we take 12 monthly mean $Z_{0}$ fields derived in Prigent et al. (2005) and re-grid the data to the same horizontal resolution as which is used for running ECHAM5-HAM (T63 in this study, cf., Sect. 3). Figure 1 presents the updated annual mean $Z_{0}$ field with the horizontal resolution of T63 (roughly $1.8^{\circ} \times 1.8^{\circ}$ ). The updated $Z_{0}$ is generally higher than $0.01 \mathrm{~cm}$ in all seasons and in most of the dust source areas, which is increased by one order of magnitude comparing to the previously fixed value of $0.001 \mathrm{~cm}$.

\subsection{Soil moisture}

Fécan et al. (1999) parameterized the influence of soil moisture on the threshold wind friction velocity, which is a function of gravimetric soil moisture $w$, and soil residual moisture $w^{\prime}$.

$\frac{U_{t w}^{*}}{U_{t}^{*}}=1 \quad$ for $\quad w<w^{\prime}$

$\frac{U_{t w}^{*}}{U_{t}^{*}}=\left[1+1.21\left(w-w^{\prime}\right)^{0.68}\right]^{0.5} \quad$ for $\quad w>w^{\prime}$

$w^{\prime}=0.0014 \times(\% \text { clay })^{2}+0.17 \times(\%$ clay $)$

$U_{t}^{*}$ is the threshold wind friction velocity in dry soil conditions, $U_{t w}^{*}$ is the threshold wind friction velocity including the effect of soil moisture conditions. $w^{\prime}$ can be obtained from the clay content with a unit of \% (Fécan et al., 1999). In ECHAM5-HAM we take values of $w^{\prime}$ from Werner et al. (2002) for the 12 prescribed soil types.

We include the parameterization of the soil moisture effect (Eqs. 3 and 4) into the improved dust emission scheme. The model predicted soil moisture $w$ is obtained from the standard ECHAM5 output, and a soil particle density of $2.65 \mathrm{~g} \mathrm{~cm}^{-3}$ is used.

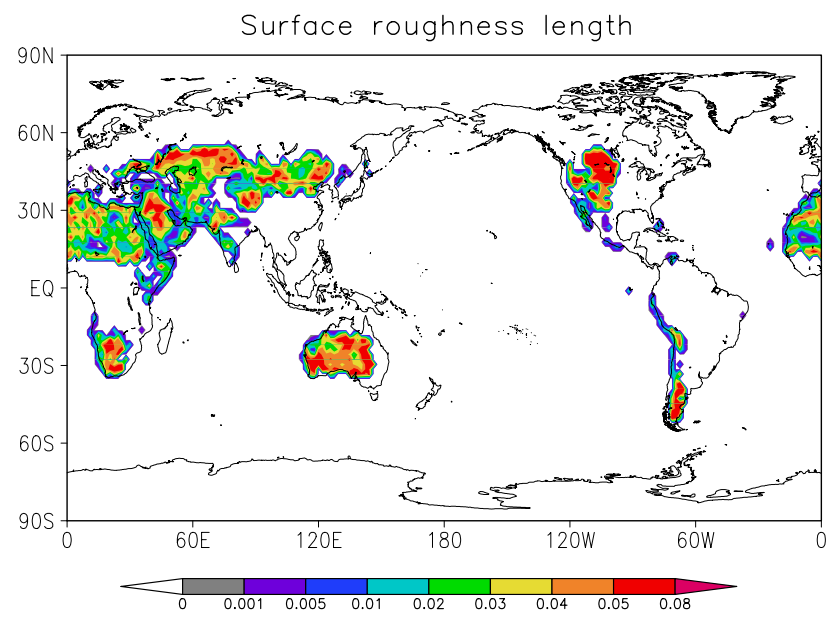

Fig. 1. Updated annual mean field of aerodynamic surface roughness length $Z_{0}(\mathrm{~cm})$ with a horizontal resolution of $1.8^{\circ} \times 1.8^{\circ}$ (Prigent et al., 2005). Data are shown only in arid and semi-arid areas of the globe, forests and dense vegetated regions are excluded because they are not potential dust source areas.

\subsection{East-Asian soil properties}

East Asia is one of the largest dust source regions in the globe. For example, arid and semiarid lands occupy 3.57 million $\mathrm{km}^{2}$ in China, distributed from west to east as the Taklimakan, Gurbantunggut, Tsaidam Basin, Kumutage, Badian Juran, Tengger, Ulan Buh, Hobq, Mu Us deserts and other small deserts. Desert plains and Gobi also occupy a large portion of Mongolia. Over these vast areas, dust storms are frequent and sometimes severe, especially from late spring to early summer. Moreover, an ongoing desertification due to overgrazing and unreasonable land use has been identified in China (Zha and Gao, 1997) and Mongolia (Natsagdorj et al., 2003), which results in additional dust sources.

In the previous emission scheme of ECHAM5-HAM, soil texture was derived from the FAO/UNESCO soil map of the World (Zobler, 1986; Tegen et al., 2002), which results in a significant underestimate of the dust emission amount in East Asia. Recently many studies investigate East-Asian soil properties into details. The map of updated soil types in China and Mongolia is obtained according to the spatial distribution of geographic land and surface vegetation types, as well as in-situ measurements of soil particle size and soil textures (Xu et al., 2006). Soils in China and Mongolia (75 to $130^{\circ} \mathrm{N}, 34^{\circ}$ to $50^{\circ} \mathrm{E}$ ) are categorized into 5 groups, according to respective locations and characteristic soil textures (Mei et al., 2004), namely Taklimakan, Loess, Gobi, desert and sand land, and other mixture soils (Table 1). The area percentage of the 5 soil types in the model grid box at East Asia are plotted in Fig. 2 with a horizontal resolution of $1.8^{\circ} \times 1.8^{\circ}$. 
Table 1. Statistical parameters (MMD, $\sigma, \mathrm{P})$ of mass-size log-normal distribution in fine and coarse modes, clay and silt contents, ratio of the vertical to horizontal dust fluxes $(\alpha)$ and residual soil moisture $\left(\mathrm{w}^{\prime}\right)$ for the 5 updated soil types in East-Asian dust source areas.

\begin{tabular}{|c|c|c|c|c|c|c|c|c|c|c|}
\hline & \multicolumn{3}{|c|}{ Fine mode } & \multicolumn{3}{|c|}{ Coarse mode } & \multirow{2}{*}{$\begin{array}{l}\text { Clay } \\
{[\%]}\end{array}$} & \multirow{2}{*}{$\begin{array}{l}\text { Silt } \\
{[\%]}\end{array}$} & \multirow{2}{*}{$\begin{array}{l}\alpha \\
{\left[\mathrm{cm}^{-1}\right]}\end{array}$} & \multirow[t]{2}{*}{$\mathrm{w}^{\prime}$} \\
\hline & $\begin{array}{l}\mathrm{MMD}_{1} \\
{[\mu \mathrm{m}]}\end{array}$ & $\sigma_{1}$ & $\begin{array}{l}\mathrm{P}_{1} \\
{[\%]}\end{array}$ & $\begin{array}{l}\mathrm{MMD}_{2} \\
{[\mu \mathrm{m}]}\end{array}$ & $\sigma_{2}$ & $\begin{array}{l}\mathrm{P}_{2} \\
{[\%]}\end{array}$ & & & & \\
\hline Taklimakan & 84 & 1.5 & 85 & 442 & 1.5 & 3 & 2 & 11 & $1.9 \mathrm{e}-06$ & 0.12 \\
\hline Loess & 70 & 1.5 & 33 & 450 & 1.5 & 0 & 17 & 50 & $1.9 \mathrm{e}-04$ & 0.15 \\
\hline Gobi & 86 & 1.5 & 22 & 457 & 1.8 & 31 & 12 & 34 & $3.9 \mathrm{e}-05$ & 0.13 \\
\hline Desert and sand land & 101 & 1.5 & 41 & 305 & 1.5 & 46 & 3 & 10 & $2.8 \mathrm{e}-06$ & 0.12 \\
\hline Other mixture soils & 90 & 1.5 & 16 & 293 & 1.8 & 39 & 10 & 35 & $3.1 \mathrm{e}-05$ & 0.13 \\
\hline
\end{tabular}
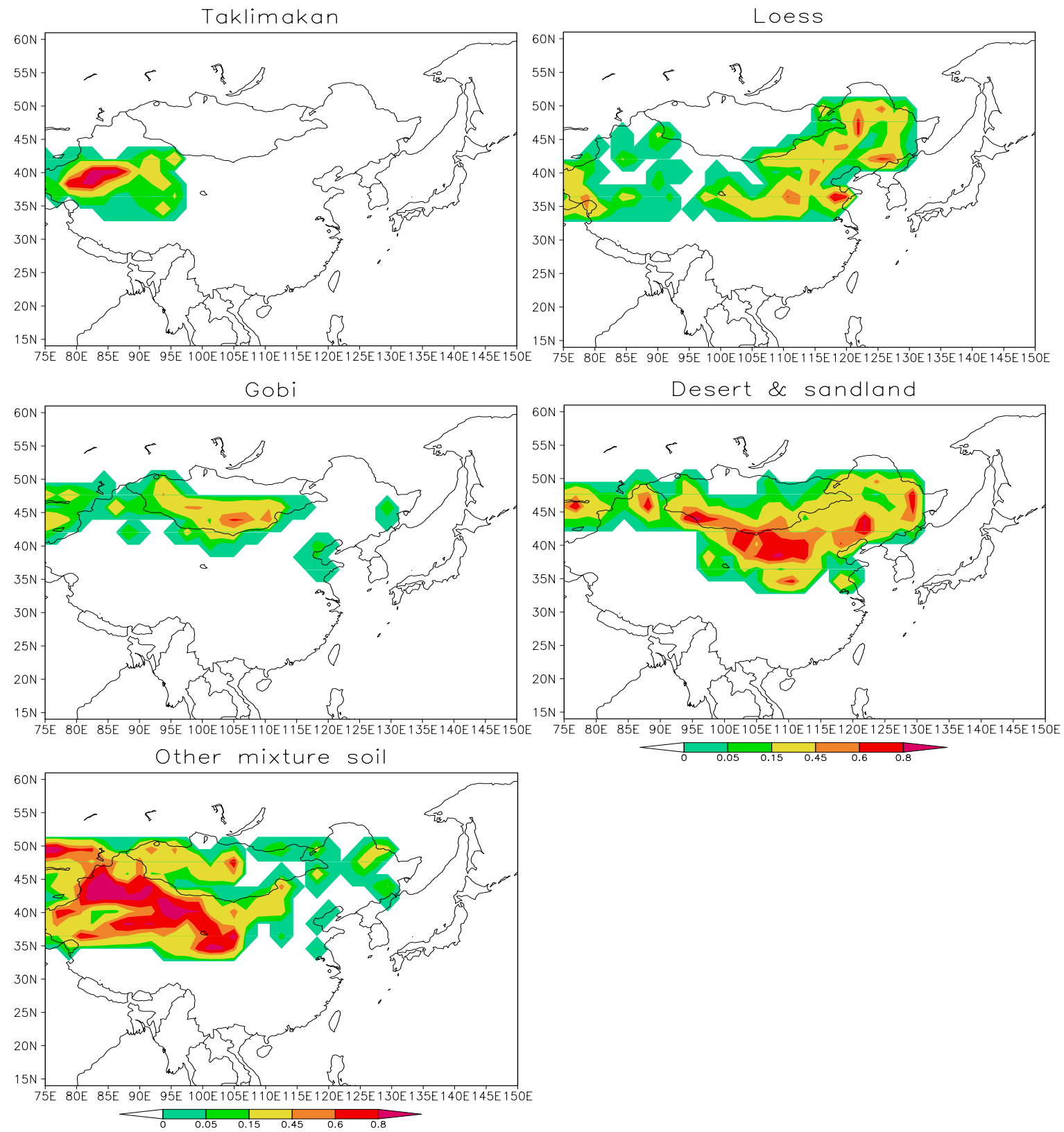

Fig. 2. Area percentages of 5 updated soil types in East-Asian dust source areas with a horizontal resolution of $1.8^{\circ} \times 1.8^{\circ}$. 
Table 2. Reference and six sensitivity simulations of ECHAM5-HAM for the year 2000: global annual mean of dust emission amount, atmospheric dust burden, total aerosol optical thickness (AOT) and dust AOT.

\begin{tabular}{lllllllll}
\hline Case & $\begin{array}{l}\text { East- } \\
\text { Asian soil } \\
\text { properties }\end{array}$ & $\begin{array}{l}\text { Surface } \\
\text { roughness } \\
\text { length } Z_{0}\end{array}$ & $\begin{array}{l}\text { Residual } \\
\text { soil } \\
\text { moisture } \\
\mathrm{w}^{\prime}\end{array}$ & $\begin{array}{l}\text { Wind } \\
\text { stress } \\
\text { correction } \\
\text { factor }\end{array}$ & $\begin{array}{l}\text { Dust } \\
\text { emission } \\
{\left[\mathrm{Tg} \mathrm{yr}^{-1}\right]}\end{array}$ & AOT & Dust AOT & $\begin{array}{l}\text { Dust } \\
\text { burden } \\
{[\mathrm{Tg}]}\end{array}$ \\
\hline 0 & No & No & No & 0.86 & 736 & 0.13 & 0.0118 & 9.78 \\
1 & No & Yes & No & 0.86 & 173 & 0.12 & 0.0030 & 2.49 \\
2 & No & No & Yes & 0.86 & 719 & 0.13 & 0.0116 & 9.64 \\
3 & Yes & No & No & 0.86 & 858 & 0.13 & 0.0128 & 10.48 \\
4 & Yes & Yes & Yes & 0.86 & 205 & 0.12 & 0.0032 & 2.70 \\
5 & Yes & Yes & Yes & 0.56 & 1671 & 0.15 & 0.0292 & 23.60 \\
6 & No & No & No & 0.56 & 3476 & 0.18 & 0.0567 & 46.00 \\
\hline
\end{tabular}

Two major soil properties are required for implementing the dust emission scheme into models: (1) the soil size distribution of in-situ erodible grains and aggregates; (2) the soil texture. Based on intensive samplings in the main Chinese arid areas, Mei et al. (2004) and Yang et al. (2001) have determined the typical micro-aggregated size distribution of surface erodible soils following the approach of Chatenet et al. (1996). For each of these 5 soil type, the mass-size distribution is fitted to two lognormal functions in fine and coarse modes, with respective parameters of mass median diameter (MMD), standard deviation $(\sigma)$ and mass fraction $(P)$. It is, however, essential to note that the size of Chinese desert soil particles in both fine and coarse modes are significantly smaller than that of Saharan soils (Chatenet et al., 1996), which explains the underestimation of emission amount in previous simulations with ECHAM5-HAM. Table 1 summarizes the statistical parameters (MMD, $\sigma$ and $P$ for fine and coarse modes respectively) of 5 updated soil types in potential dust source areas of China and Mongolia.

In addition to the soil size distribution, Mei et al. (2004) investigated the soil textures in the corresponding Chinese arid areas. The overall median clay contents of Chinese soils (Laurent et al., 2006) are comparable to the North American (Marticorena et al., 1997b) and Saharan (Chatenet et al., 1996) soils. Ding et al. (1999) measured the soil clay contents of Chinese loess and sandy loess. A typical value of $17 \%$ is taken as the representative for the clay content of loess (Table 1). Similarly, the silt content, the ratio of vertical to horizontal dust fluxes $(\alpha)$ and the soil residual moisture $\left(w^{\prime}\right)$ for 5 updated soil types are obtained (Laurent et al., 2006), and summarized in Table 1. The updated data of soil types, size distributions and soil textures in East-Asian dust source areas replace the previous input in the improved dust emission scheme of ECHAM5-HAM.

\section{Results}

\subsection{Evaluation on the improved dust emission scheme}

ECHAM5-HAM simulations are performed for the year 2000 after a spin-up time of three months. Temperature, pressure and horizontal wind velocities are nudged to the ECMWF ERA40 reanalysis data. The model uses horizontal resolution of T63 and has 31 hybrid levels vertically. Seven experiments are run to examine the sensitivity of global dust emissions to modifications in the improved scheme. Case 0 is the reference simulation with the original dust emission scheme. Case 1 to case 3 are simulations including the update of $Z_{0}$, soil moisture and East-Asian soil properties respectively. Case 4 is the simulation of ECHAM5-HAM with the improved dust emission scheme. In case 5 we artificially tune a parameter of wind stress correction factor, which is a constant number over the globe and reduces the threshold wind friction velocity proportionally. The tuning parameter is necessary to obtain a global annual mean emission amount within a range of available estimates. However, including the parameter does not directly modify the spatial and temporal distribution of dusts (Timmreck and Schulz, 2004). In case 6 we rerun the reference case with the tuned threshold wind friction velocity.

Table 2 lists the setup of seven simulations and the corresponding results as annual global means of dust emission amount, atmospheric dust burden, total aerosol optical thickness (AOT) and dust AOT. The inclusion of updated $Z_{0}$ field and soil moisture results in $76.5 \%$ and $2.2 \%$ decreases of the dust emission amount, while the modified East-Asian soil properties lead to an increase of $16.6 \%$. Changes in the dust burden, total AOT and dust AOT are similar to that of emission amount. The great reduction from case 0 to case 1 is due to the generally high $Z_{0}$ in the updated field (cf., Fig. 1 and Sect. 2.1) and shows a similar trend with results in Laurent et al. $(2005,2006)$ and Tegen et al. (2004). The increase from case 0 to case 3 as a result of modified East-Asian soil 

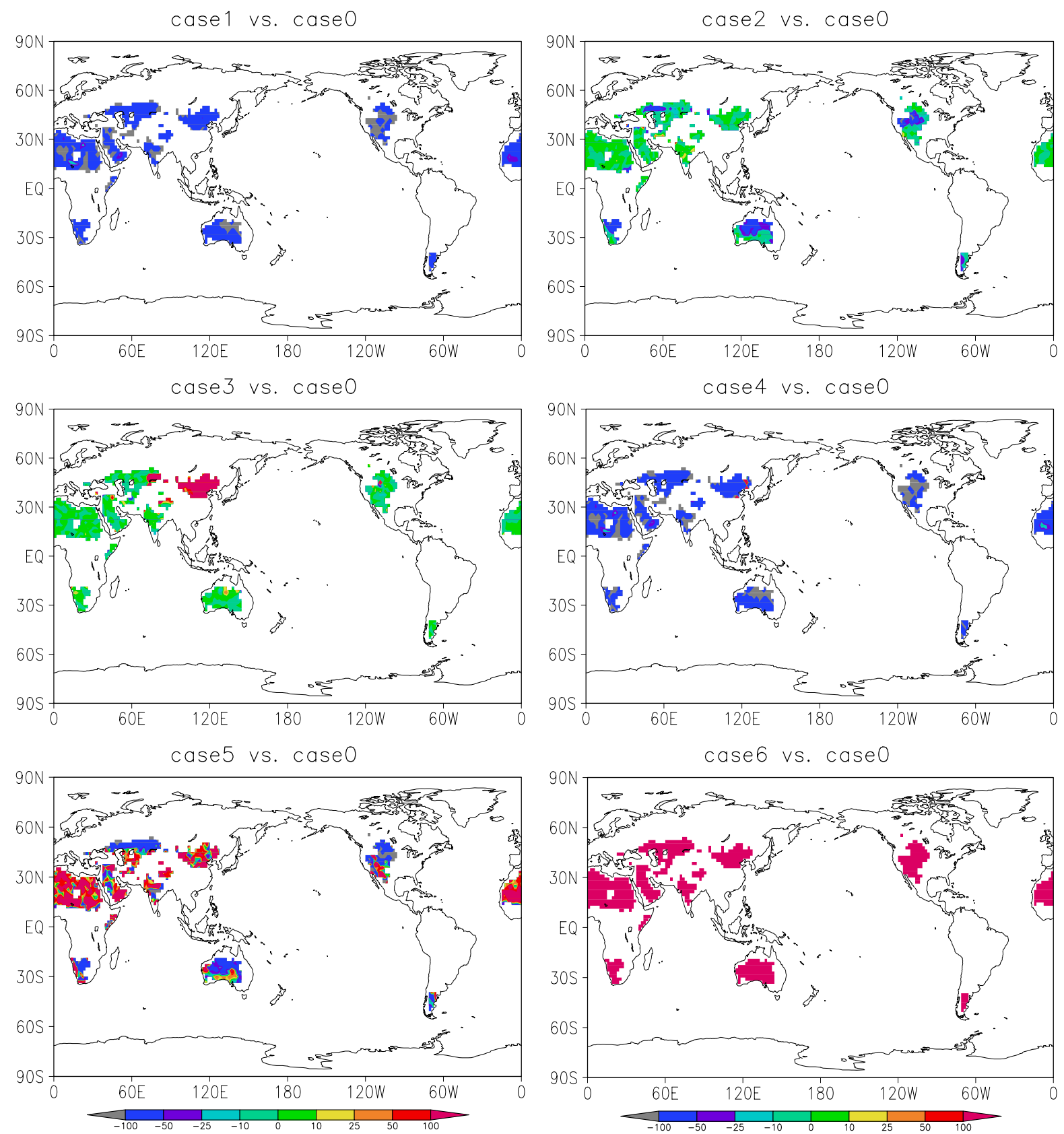

Fig. 3. Percentage differences (\%) between sensitivity simulations and the reference simulation in terms of the annual mean dust emission amount $\left(\mathrm{Tg} \mathrm{yr}^{-1}\right.$, global mean values are listed in column 6 of Table 2).

properties leads to a better agreement with measurements, as will be seen in Sect. 3.2.

The more physically-based dust emission scheme reduces the emission amount dramatically (case 4 vs. case 0 ). Therefore the wind stress correction factor has to be lowered in order to decrease the threshold wind friction velocity and to enhance the emission (same approach as in Timmreck and Schulz, 2004). As the wind stress correction factor varies from 0.86 to 0.56 the resulted emission amount is around $1670.7 \mathrm{Tg} \mathrm{yr}^{-1}$ (case 5), which falls in the range of 1000 to $3000 \mathrm{Tg} \mathrm{yr}^{-1}$ as estimated by IPCC (2007). It also agrees to the median of model estimates in AeroCom (http://nansen.ipsl.jussieu.fr/AEROCOM/), which is $1770 \mathrm{Tg} \mathrm{yr}^{-1}$. In case 5 the total AOT is 0.15 , which falls in the range of 0.116 to 0.155 suggested by AeroCom model inter-comparison (Kinne et al., 2006). The total AOT is also similar to the estimated value of 0.14 as derived from AERONET measurements (Kinne et al., 2003). 
Table 3. List of annual mean surface dust concentration $\left(\mu \mathrm{g} \mathrm{m}^{-3}\right)$ used in Fig. 4: measurements are taken from global remote marine sites by University of Miami network. Model results in the corresponding site are taken from simulations of year 2000 with the original and improved dust emission scheme (case 0 and case 5) respectively.

\begin{tabular}{llllll}
\hline Location & Longitude & Latitude & Measurement & Case 0 & Case 5 \\
\hline Cape Point - South Africa & 18.5 & -34.3 & 2.20 & 0.28 & 0.13 \\
Marsh - King George Island & -58.3 & -62.2 & 0.52 & 0.0008 & 0.0008 \\
Mawson - Antarctica & 62.5 & -67.6 & 0.10 & 0.0002 & 0.0002 \\
Palmer Station - Antarctica & -64.1 & -64.8 & 0.35 & 0.0002 & 0.0001 \\
Yate - New Caledonia & 167.0 & -22.1 & 0.17 & 0.45 & 0.56 \\
Funafuti - Tuvalu & -179.2 & -8.5 & 0.19 & 0.006 & 0.02 \\
Nauru & 166.9 & -0.5 & 0.10 & 0.007 & 0.03 \\
Norfolk Island & 168.0 & -29.1 & 0.84 & 0.52 & 0.75 \\
Rarotonga - Cook Islands & -159.8 & -21.2 & 0.11 & 0.069 & 0.14 \\
American Samoa & -170.6 & -14.2 & 0.16 & 0.0045 & 0.006 \\
Midway Island & -177.4 & 28.2 & 0.72 & 0.054 & 0.15 \\
Oahu Hawaii & -157.7 & 21.3 & 0.66 & 0.023 & 0.063 \\
Cheju - South Korea & 126.5 & 33.5 & 14.14 & 7.75 & 14.11 \\
Hedo Okinawa - Japan & 128.2 & 26.9 & 8.37 & 3.30 & 6.57 \\
Fanning Island & -159.3 & 3.9 & 0.10 & 0.0063 & 0.02 \\
Enewetak Atoll & 162.3 & 11.3 & 0.24 & 0.008 & 0.03 \\
Barbados & -59.4 & 13.2 & 14.48 & 7.70 & 14.62 \\
Izana Tenerife & -16.5 & 28.3 & 30.18 & 20.55 & 43.38 \\
Bermuda & -64.9 & 32.3 & 3.36 & 0.85 & 1.64 \\
Mace Head - Ireland & -9.9 & 53.3 & 1.00 & 0.28 & 0.67 \\
Miami & -80.2 & 25.8 & 4.59 & 2.08 & 3.78 \\
\hline Average & - & - & 3.93 & 2.09 & 4.13 \\
\hline
\end{tabular}

Figure 3 shows the percentage differences between sensitivity simulations and the reference simulation in terms of the annual mean dust emission amount. Large decreases exhibit globally due to the high values of $Z_{0}$ in the updated field (case 1 vs. case 0 ), while great reduction occurs in North America desert and part of Sahara, Australia, India and Middle East deserts. The change of soil moisture parameterization results in decreases in part of North America, Australia, South Africa and Middle East deserts, as well as small increases in India and Middle Asia (case 2 vs. case 0). An exclusive enhancement in arid and semi-arid areas of northern China and southern Mongolia (case 3 vs. case 0 ) is caused by the modified East-Asian soil properties. It is worth mentioning that the general pattern of dust seasonal cycle is not significantly influenced by the improved emission scheme (not shown). The decrease due to the updated $Z_{0}$ field dominates and contributes to the global reduction from case 0 to case 4 , although modified East-Asian soil properties are responsible for an enhancement in the specific region. Lowering the wind stress correction factor from 0.86 to 0.56 leads to an overall large increase (case 6 vs. case 0), which compensates the reduction from the improved emission scheme.

There are few observations of the global dust distribution and no direct measurements of dust emissions are available. Nevertheless, we compare the simulated dust mass concen- tration at the lowest model level with the surface measurements in multiple remote marine sites (similar to the comparison in Stier et al., 2005), in order to evaluate the improved dust emission scheme in ECHAM5-HAM. Figure 4 presents a comparison of annual mean surface dust mass concentrations (data are listed in Table 3). Measurements are averaged from multiyear observations at 21 remote marine sites by University of Miami network. Model results are derived from ECHAM5-HAM simulations in year 2000 with and without the improved dust emission scheme (case 5 and case 0 in Table 3 respectively). The mineral dust mass concentrations of Miami network were derived from the measured aluminum concentration in samples of total suspended particulate matter (TSP) on the assumption that mineral dust aerosols have an aluminum content equal to that of average soils, which is suggested to be $8 \%$ (Prospero, 1999). The dust mass concentrations are generally underestimated by the model. Particularly low values of model predictions are noticeable (Note that Fig. 4 uses the logarithm scale. Some model estimates are below 0.01 but all measurements are above 0.1 ). One possible explanation is that model simulations are limited in the year 2000 while measurements are climatologically. Moreover, simplifications of the dust relevant processes in the model, e.g., the neglect of super-coarse mode emission, an overestimation of sink processes for example an 


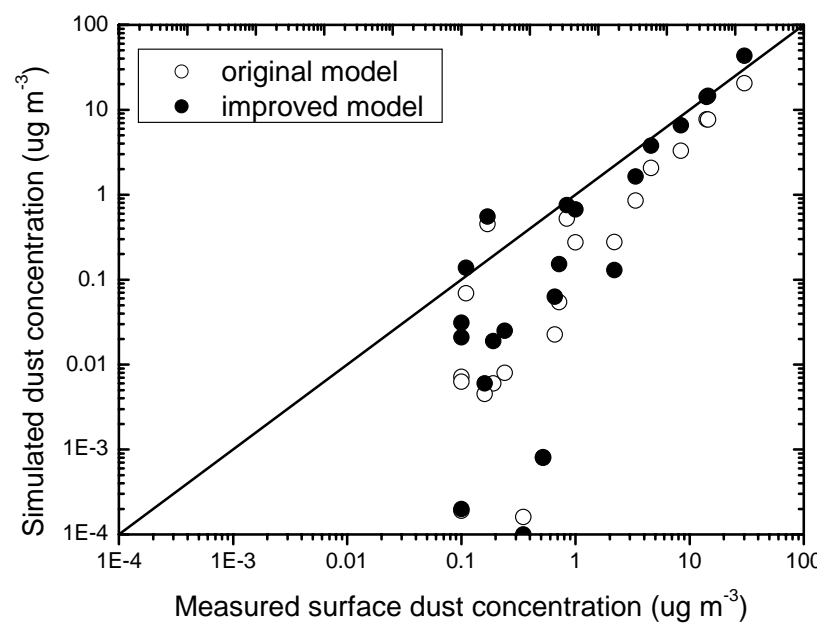

Fig. 4. A comparison of annual mean surface dust concentration between measurements at remote marine sites and corresponding model results. Data and site locations are listed in Table 3. Solid line is the 1 to 1 line. Logarithm scale is used in order to show some low values of model results. The averaged relative difference is $17 \%$ between original model results and measurements, and is $12 \%$ between the improved model results and measurements.

excessive microphysical aging, could potentially contribute to this large discrepancy.

Despite the large discrepancy in the individual site, results of case 5 show a better agreement to the measurements (see average values in Table 3 and averaged relative difference in Fig. 4). Also noticed that in sites where concentration is higher than $5 \mu \mathrm{g} \mathrm{m}^{-3}$, case 5 results are more close to the measurements than case 0 (Table 3), indicating an efficient improvement in dusty regions. Including the improved dust emission scheme in ECHAM5-HAM raises the predicted surface dust concentrations, approaching to the measured values in most of northern hemisphere sites, especially in East Asia and the pacific islands (cf., data and locations in Table 3). However, case 5 still underestimates the surface dust concentrations for most of southern hemisphere sites, which could be attributed to unrealistic soil properties and underestimation of wind speed in this region in the model.

\subsection{Evaluation on East-Asian dust emission}

The atmospheric visibility is affected by the presence of aerosols and water vapor. During a dust episode, it is reasonable to assume that dust aerosol plays a determining role and thus the dust concentration can be estimated from visibility measurements. As one of the regular weather station records, visibility data provides good spatial and temporal coverage in China during recent years. We derive the surface dust concentration from selected visibility records, following the empirical relationships in Shao et al. (2003). The visibility data in non-dusty days are excluded, in order to rule out the impacts of other aerosol species. Note that the derived dust concentration from visibility observations may overestimate the realistic dust amount to some extent, due to the impact of air moisture on visibility. However, the empirical coefficients and the subjective observations on visibility introduce additional uncertainties. The derived dust concentrations exhibit a certain spatial pattern and can be a good reference for an evaluation on the model results in Asian area.

Figure 5 shows a comparison of monthly mean surface dust concentration in April of 2001 between the observed data derived from visibility and ECHAM5-HAM simulation results of case 0 and case 5. Dust storm prevails and dust activities are highly frequent in spring, therefore, the derived data are more reliable during this period. Both simulations can reproduce the pattern of dust source regions in Northern China. Over northwestern China, where the Tsaidam basin and the Kumutage desert are located, and in Northeast China, results of case 5 are more consistent with observations both in area extent and in magnitude. Case 5 also captures high dust concentrations along the boundary between Mongolia and Northeast China.

The improvement from case 0 to case 5 is mainly attributed to the increased emissions. In Fig. 6 relative differences between the two cases are plotted in terms of the monthly mean dust emission amount in April of 2001 (note that this is different from the panel of case 5 vs. case 0 in Fig. 3, which is for an annual global dust emission amount). Dust emissions are dramatically enhanced in Taklimahan desert, Hexi Corridor region and in Northeast China, which is due to a high fraction of fine mode particles in these regions in the improved scheme (cf. Table 1 and Fig. 2). The monthly mean emission amount in April 2001 is increased by 92.8\% from case 0 to case 5 in the plotted area of Fig. 6 . The 5 additional soil types represent the soil properties more realistically in East Asia. Thus the model performance is largely improved in this region.

Few direct measurements of dust emission are available in East Asia. Alternatively, near-surface dust concentrations are measured in various locations of northern Asia by the China Dust Storm Research (ChinaDSR) during spring 2001 (Zhang et al., 2003), as part of the Asia Pacific Regional Aerosol Characterization Experiment (ACE-Asia), as well as by the Aeolian Dust Experiment on Climate (ADEC) from 2001 to 2004 (Kanai et al., 2005; Yabuki et al., 2005; Kim et al., 2003, 2006). Measurements taken from 16 stations are compared to model predictions in the corresponding time of 2001 and 2002 (Table 4 and Fig. 7). The selected stations are located in or downstream of the dust source regions (Table 4), with ten in China (Aksu, Dunhuang, Yulin, Changwu, Lanzhou, Shapotou, Inner-Mongolia, Beijing, Hefei and Qingdao), two in South Korea (Seoul and Gosan) and four in Japan (Tsukuba, Nagoya, Fukuoka and Naha). In these locations, dust mass concentrations are derived from the total aerosol loading and the average percentage of mineral matter, the latter is calculated from the sum 
Table 4. List of monthly mean near-surface dust concentration $\left(\mathrm{mg} \mathrm{m}^{-3}\right)$ used in Fig. 7. Measurements are collected from in-situ observations in northern Asia. Model results in the corresponding site and period are taken from simulations with the original and improved dust emission scheme (case 0 and case 5) respectively.

\begin{tabular}{|c|c|c|c|c|c|c|c|}
\hline Site location & Latitude & Longitude & Period & Measurement & Case 0 & Case 5 & Reference \\
\hline \multirow{5}{*}{ Aksu - China } & 40.27 & 80.47 & 2001.03 & 0.081 & 0.064 & 0.084 & Yabuki et al. (2005) \\
\hline & & & 2001.05 & 0.417 & 0.021 & 0.118 & Zhang et al. (2003) \\
\hline & & & 2002.03 & 0.531 & 0.081 & 0.245 & Yabuki et al. (2005) \\
\hline & & & 2002.04 & 0.597 & 0.145 & 0.561 & \\
\hline & & & 2002.05 & 0.179 & 0.012 & 0.036 & \\
\hline \multirow[t]{2}{*}{ Dunhuang - China } & 40.50 & 94.82 & 2001.05 & 0.212 & 0.009 & 0.026 & Zhang et al. (2003) \\
\hline & & & 2002.04 & 0.157 & 0.026 & 0.087 & Shao et al. (2003) \\
\hline \multirow[t]{3}{*}{ Zhenbeitai - China } & 38.29 & 109.70 & 2001.03 & 0.304 & 0.060 & 0.104 & Zhang et al. (2003) \\
\hline & & & 2001.04 & 0.209 & 0.199 & 0.347 & \\
\hline & & & 2001.05 & 0.127 & 0.031 & 0.050 & \\
\hline \multirow[t]{3}{*}{ Changwu - China } & 35.02 & 107.68 & 2001.03 & 0.170 & 0.025 & 0.053 & Zhang et al. (2003) \\
\hline & & & 2001.04 & 0.211 & 0.079 & 0.215 & \\
\hline & & & 2001.05 & 0.057 & 0.022 & 0.043 & \\
\hline \multirow[t]{3}{*}{ Lanzhou - China } & 36.05 & 103.88 & 2001.03 & 0.328 & 0.013 & 0.029 & Zhang et al. (2003) \\
\hline & & & 2001.04 & 0.305 & 0.060 & 0.162 & \\
\hline & & & 2001.05 & 0.164 & 0.026 & 0.042 & \\
\hline \multirow[t]{4}{*}{ Shapotou - China } & 37.50 & 105.00 & 2001.03 & 0.470 & 0.022 & 0.047 & Zhang et al. (2003) \\
\hline & & & 2001.04 & 0.370 & 0.143 & 0.389 & \\
\hline & & & 2001.05 & 0.157 & 0.033 & 0.077 & \\
\hline & & & 2002.04 & 0.111 & 0.039 & 0.082 & Shao et al. (2003) \\
\hline Inner Mongolia - China & 42.67 & 115.95 & 2001.04 & 0.447 & 0.197 & 0.474 & Cheng et al. (2005) \\
\hline \multirow[t]{5}{*}{ Beijing - China } & 39.93 & 116.35 & 2001.03 & 0.252 & 0.054 & 0.128 & Zhang et al. (2003) \\
\hline & & & 2001.04 & 0.206 & 0.142 & 0.257 & \\
\hline & & & 2001.05 & 0.133 & 0.061 & 0.096 & \\
\hline & & & 2002.03 & 0.282 & 0.058 & 0.113 & Kanai et al. (2005) \\
\hline & & & 2002.04 & 0.267 & 0.071 & 0.169 & \\
\hline \multirow[t]{3}{*}{ Qingdao - China } & 36.07 & 120.33 & 2001.05 & 0.026 & 0.020 & 0.041 & Kanai et al. (2005) \\
\hline & & & 2002.03 & 0.083 & 0.056 & 0.098 & \\
\hline & & & 2002.04 & 0.055 & 0.042 & 0.095 & \\
\hline Hefei - China & 31.90 & 117.16 & 2002.03 & 0.066 & 0.042 & 0.072 & Kanai et al. (2005) \\
\hline \multirow[t]{3}{*}{ Seoul - South Korea } & 37.53 & 127.07 & 2001.03 & 0.113 & 0.016 & 0.044 & Kim et al. (2006) \\
\hline & & & 2001.04 & 0.093 & 0.038 & 0.100 & \\
\hline & & & 2001.05 & 0.076 & 0.006 & 0.026 & \\
\hline Gosan - South Korea & 33.29 & 126.16 & 2001.04 & 0.052 & 0.031 & 0.056 & Kim et al. (2003) \\
\hline \multirow[t]{5}{*}{ Tsukuba - Japan } & 36.06 & 140.14 & 2001.03 & 0.035 & 0.004 & 0.011 & Kanai et al. (2005) \\
\hline & & & 2001.04 & 0.036 & 0.008 & 0.033 & \\
\hline & & & 2001.05 & 0.029 & 0.005 & 0.011 & \\
\hline & & & 2002.03 & 0.049 & 0.016 & 0.029 & \\
\hline & & & 2002.04 & 0.049 & 0.014 & 0.036 & \\
\hline \multirow[t]{5}{*}{ Nagoya - Japan } & 35.15 & 136.96 & 2001.03 & 0.034 & 0.006 & 0.015 & Kanai et al. (2005) \\
\hline & & & 2001.04 & 0.038 & 0.010 & 0.039 & \\
\hline & & & 2001.05 & 0.027 & 0.006 & 0.013 & \\
\hline & & & 2002.03 & 0.030 & 0.011 & 0.033 & \\
\hline & & & 2002.04 & 0.054 & 0.019 & 0.048 & \\
\hline \multirow[t]{3}{*}{ Fukuoka - Japan } & 33.55 & 130.37 & 2001.05 & 0.045 & 0.004 & 0.022 & Kanai et al. (2005) \\
\hline & & & 2002.03 & 0.062 & 0.017 & 0.046 & \\
\hline & & & 2002.04 & 0.060 & 0.028 & 0.066 & \\
\hline \multirow[t]{2}{*}{ Naha - Japan } & 26.20 & 127.69 & 2002.03 & 0.033 & 0.005 & 0.012 & Kanai et al. (2005) \\
\hline & & & 2002.04 & 0.046 & 0.007 & 0.020 & \\
\hline Average & - & - & - & 0.162 & 0.043 & 0.102 & - \\
\hline
\end{tabular}



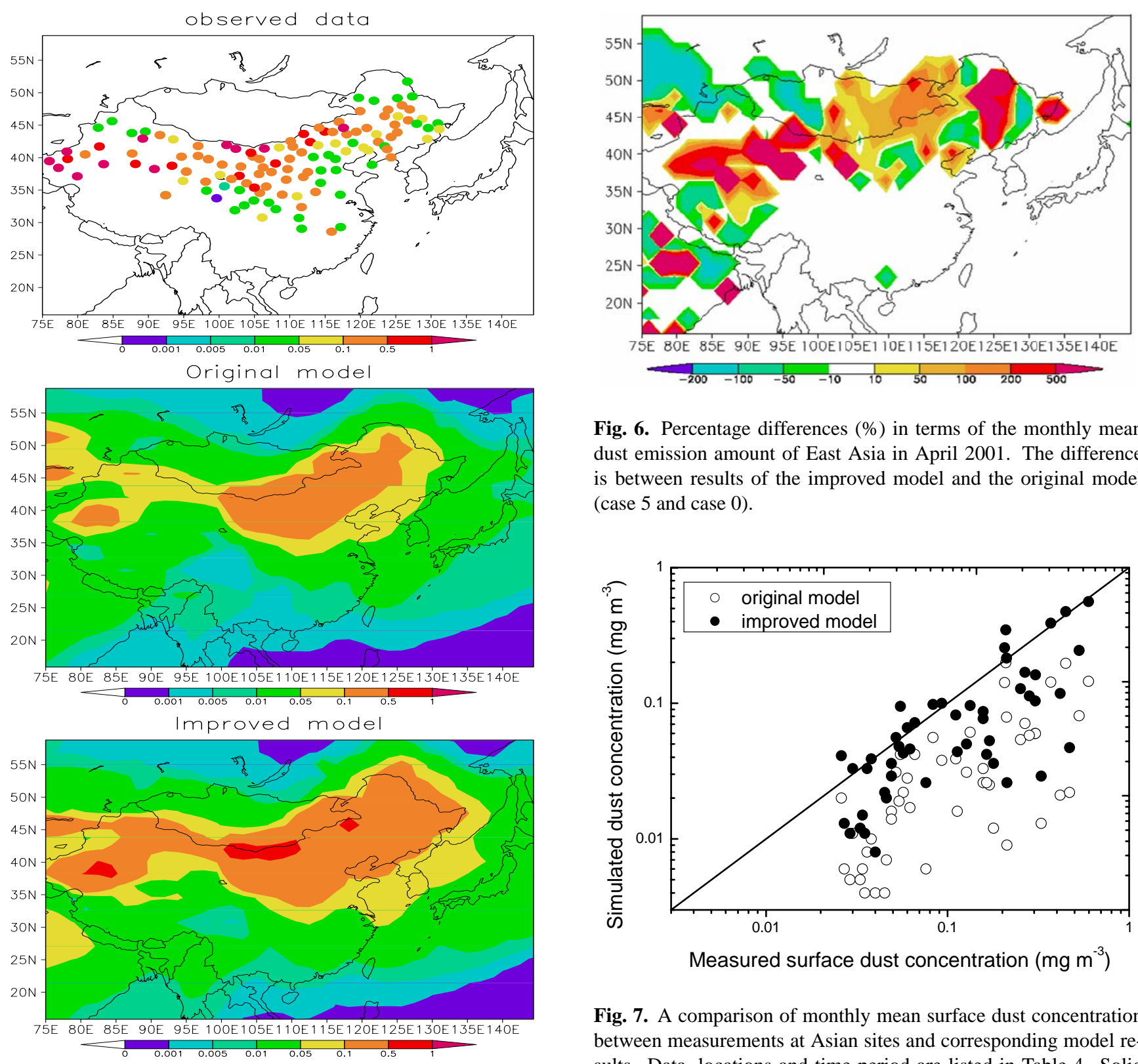

Fig. 6. Percentage differences (\%) in terms of the monthly mean dust emission amount of East Asia in April 2001. The difference is between results of the improved model and the original model (case 5 and case 0 ).

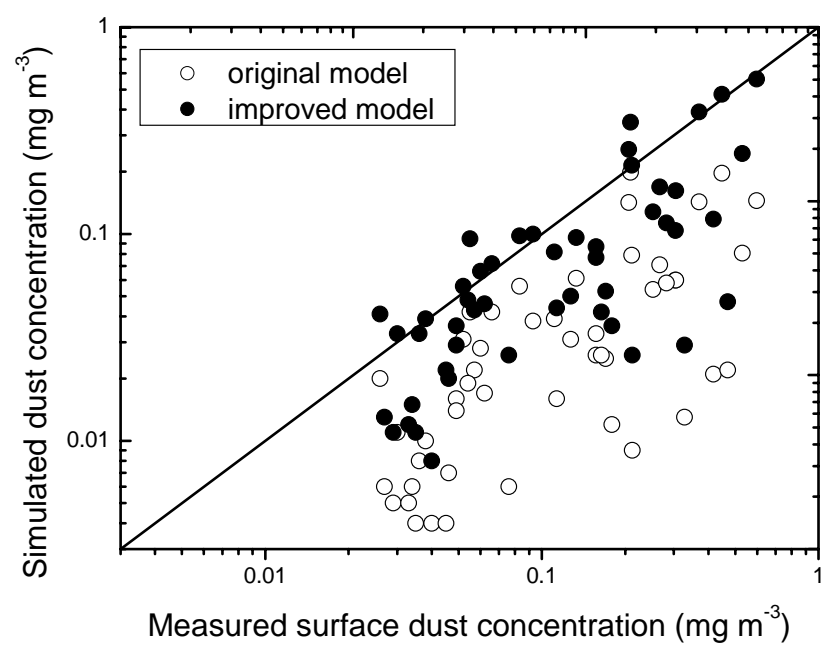

Fig. 7. A comparison of monthly mean surface dust concentration between measurements at Asian sites and corresponding model results. Data, locations and time period are listed in Table 4. Solid line is the 1 to 1 line. Logarithm scale is used in order to show some low values of model results. The averaged relative difference is $69 \%$ between original model results and measurements, and is $30 \%$ between the improved model results and measurements.

Fig. 5. A comparison of monthly mean surface dust concentration $\left(\mathrm{mg} \mathrm{m}^{-3}\right)$ in East Asia at April, 2001. The observed data are derived from visibility. Dust concentrations between 0.001 and $1 \mathrm{mg}$ $\mathrm{m}^{-3}$ as indicated in the color bar are corresponding to visibilities of 69.2, 54.7, 48.4, 33.8, 27.5, 12.8 and $6.5 \mathrm{~km}$ respectively (Shao et al., 2003). Model results are taken from simulations with the original and improved dust emission scheme (case 0 and case 5) respectively.

of aluminum, silicon, calcium and iron oxides of intense aerosol samples following an empirical function (Solomon et al., 1989). ADEC data in Japan are almost continuous, whereas observations in China are carried out during dust events, thus high concentrations may be sampled (Kanai et

al., 2005). Note that the measurement data show an average of dust mass concentration during the operation period.

The near-surface measurement data are compared to ECHAM5-HAM simulations of case 0 and case 5 in Fig. 7 (data are listed in Table 4). In most stations, results of case 5 are in better agreement with observations than case 0 , especially in areas of East China, South Korea and Japan (cf., data in Table 4). Figure 7 shows that in about $75 \%$ of stations the concentration has more than doubled from case 0 to case 5, and approaches to the measured values. Comparisons 
in Fig. 5 and Fig. 7 show largely improvements both in the model performance and in the predicted dust concentrations in East Asia, which is mainly resulted from the modified soil properties in this region.

Although the improved dust emission scheme enables to produce a more realistic result in East Asia, the model still underestimates the dust surface concentration in source regions of northwestern China (cf., Fig. 5). One possible reason for the discrepancy is the coarse spatial resolution of ECHAM5-HAM grid box, in which the secondary dust sources, small scale synoptic systems, regional topography and geomorphology are not well solved. Most of the sandy deserts in China and Mongolia are located in closed basins, surrounded by stony hills and mountains. For example, the Taklimakan desert is in the closed basin of Tarim, the Gurban Tonggut desert lies in the basin of Junhhaar, both Badain Jaran and Tengger deserts are in the basin of Hanhai. Specific air circulations can be induced in such low-altitude locations. For instance, the Tarim basin is surrounded in three directions by Kulun Mounts, which is higher than $5000 \mathrm{~m}$. Winds in this region are northeasterly except for the western margins (Sun, 2002). As a result, dusts from the Taklimakan desert remain confined in the southwestern slope of Kulun Mounts. On the other hand, the differences between model simulation and measurements are likely due to the lack of precise maps of surface features in East Asia, especially the soil clay content and erodible fraction of the surface. The neglect of super-coarse mode particles also possibly contributes to the underestimation when gusty wind prevails.

\section{Discussions}

Near-surface wind velocity is one key factor to control the saltation and erosion of soil particles. Dust emissions are particularly sensitive to small differences in wind speed because the parameterized emission flux is proportional to the third power of surface wind stress. We compare the monthly mean wind speeds observed in East-Asian dust source regions with the simulated wind speeds at $10 \mathrm{~m}$ height above the surface in ECHAM5-HAM, during a dust active period of April, 2001 (results are not shown). The mean wind speed is generally underestimated by the model. The underestimation is even stronger where high wind speed is observed. Tegen et al. (2002) reported the similar underestimations on wind speed and on the maximum wind speed by the large scale model. The discrepancy between the ECHAM5 simulation and observed wind speeds could be a fundamental reason for the overall underestimation of dust surface concentrations shown in present results (e.g., Fig. 4). However, investigation on this problem is beyond the scope of the current study.

In the improved emission scheme we replace the constant $Z_{0}$ with updated global $Z_{0}$ field. Additionally, the smooth roughness length $z_{0 s}$ is assumed to be constant, which is about $1 / 30$ of the coarser mass median diameter of soil size distribution in ECHAM5-HAM. It should be noted that the dust emission is very sensitive to $z_{0 s}$ in some specific regions. For example in the Taklimakan desert, the coarser population represents a very small fraction $(<3 \%)$ of soil size distribution (Mei et al., 2004). $Z_{0}$ derived from satellite data in this desert $\left(<10^{-3} \mathrm{~cm}\right)$ is lower than in other sandy deserts (Laurent et al., 2005). Therefore, $z_{0 s}$ in the Taklimakan desert is likely to be derived as $1 / 30$ of the finest mass median diameter, so that a part of smooth erodible surface can be transformed into a relatively rough and less erodible surface (Laurent et al., 2006). In order to better account for the surface feature in various locations, a map of $z_{0 s}$ will be helpful to further improve the global dust emission simulation.

Parameterized soil moisture effect in the improved emission scheme depends on the model predicted soil moisture, which is derived in the land surface scheme of ECHAM5. A homogeneous soil texture is assumed in the uppermost surface layer with a depth of $1.0 \mathrm{~m}$ and over the global land surface. As a result, the model is not able to simulate the low soil moisture content as measured in arid and semi-arid areas. For example, Van Den Hurk et al. (2000) proves that the soil moisture fields of ERA40 reanalysis data, which are derived in a land surface scheme including four prognostic soil layers with a homogeneous texture over the global land surface, does not match the low soil moisture contents measured in semi-arid areas such as Sahel. Although the general pattern and the seasonal cycle of dust emissions are not significantly influenced by the soil moisture, the moisture content of superficial soil layer contributes to dust emission in source regions. Therefore, a soil moisture field derived from a more realistic land surface scheme will help to understand the impact of climatic factors, such as precipitation, on dust emissions.

In Table 2 and Fig. 3 shows that the effect of tuning parameter of wind stress correction factor could potentially overwhelm effects of the improved scheme. However, the use of tuning parameter does not have a solid foundation of physics. The parameter is currently adapted to the respective model version in order to obtain the annual global mean dust amount within the range of available estimates. Inclusion of a more physically-based formulation and more up-to-date data in model would be taken as a preferential way in the improvement of emission scheme in global climate models.

Dust emissions are in response to near-surface wind velocity, land surface features, soil properties and moisture content directly. Additionally, anthropogenic impacts on climatic factors could influence the dust emission indirectly. For instance, natural vegetation pattern can be well modified as a consequence of land use by human being, that will change surface features and soil properties thus lead to additional dust source regions. In order to better understand the effects of climate changes on atmospheric dust distribution, a long period model simulation is necessary and year-to-year databases of soil texture and vegetation cover will be needed. 


\section{Conclusions}

An improvement on the dust emission scheme is included in the global aerosol-climate modeling system ECHAM5HAM. Modifications on the surface aerodynamic roughness length $Z_{0}$, soil moisture and East-Asian soil properties influence the calculation of threshold wind friction velocity for aeolian erosion. Update in $Z_{0}$ parameterization includes the recently derived satellite data in order to provide a more realistic map of one global input field. The improved soil moisture formulation is more physically-based than the previous model version. Changes in $Z_{0}$ and soil moisture parameterization provide a further physical constraint on the dust emission calculation in model and the resulted reductions in the annual global mean dust emission is $76.5 \%$ and $2.2 \%$ respectively. Moreover, 5 additional East-Asian soil types represent the soil texture and properties more appropriately in this region, which lead to an increase of $16.6 \%$ in the annual global mean dust emissions. Better agreement between model results and available measurements is obtained in terms of the surface dust concentration in global remote marine sites and in stations over source areas of East Asia. The averaged relative difference in remote marine sites is $17 \%$ between the original model results and measurements, which is reduced to $12 \%$ when the improved scheme is included in the model. The averaged relative difference in Asia is $69 \%$ between the original model results and measurements, and decreased to $30 \%$ with the improved model, which is mainly attributed to the modified representation of soil properties in source areas of Asia.

Acknowledgements. We thank X. Xu and C. Prigent for their helps in providing maps of East-Asian soil texture and the global surface aerodynamic roughness length $Z_{0}$. Instructive discussions with S. Kloster and C. Reader are appreciated. Y. Peng was supported by the Alexander von Humboldt foundation in Germany. The model simulation and data storage were performed at DKRZ (German Climate Computing Centre).

Edited by: Y. Balkanski

\section{References}

Chadwick, O. A., Derry, L. A., Vitousek, P. M., Huebert, B. J., and Hedin, L. O.: Changing sources of nutrients during four million years of ecosystem development, Nature, 397, 491-497, 1999.

Chatenet, B., Marticorena, B., Gomes, L., and Bergametti, G.: Assessing the microped size distributions of desert soils erodible by wind, Sedimentology, 43, 901-911, 1996.

Ding, Z. L., Ren, J. Z., Yang, S. L., and Liu, T. S.: Climate instability during the penultimate glaciation: evidence from two highresolution loess records, China, J. Geophys. Res., 104, $20123-$ $20132,1999$.

Fécan, F., Marticorena, B., and Bergametti, G.: Parameterization of the increase of the aeolian erosion threshold wind friction velocity due to soil moisture for arid and semi-arid areas, Ann. Geo- phys., 17, 149-157, 1999, http://www.ann-geophys.net/17/149/1999/.

Gillette, D. A., Adams, J., Muhs, D., and Khil, R.: Threshold friction velocities and rupture moduli for crusted desert soil for the input of soil particles into the air, J. Geophys. Res., 87, 90039016, 1982.

Gillette, D. A. and Passi, R.: Modeling dust emission caused by wind erosion, J. Geophys. Res., 93, 14 233-14 242, 1988.

Ginoux, P., Chin, M., Tegen, I., et al.: Sources and distributions of dust aerosols simulated with the GOCART model, J. Geophys. Res., 106, 20 255-20 273, 2001.

Intergovernmental Panel on Climate Change: Climate Change 2007, edited by: Solomon, S., Qin, D., Manning, M., et al., Cambridge Univ. Press, New York, 2007.

Kanai, Y., Ohta, A., Kamioka, H., et al.: Characterization of Aeolian dust in east China and Japan from 2001 to 2003, J. Meteorol. Soc. Jpn., 83A, 73-106, 2005.

Kim, K. H. and Kim, M. Y.: The effects of Asian dust on particulate matter fractionation in Seoul, Korea during spring 2001, Chemosphere, 51, 707-721, 2003.

Kim, J. Y., Yoon, S. C., Kim, S. W., et al.: Chemical apportionment of shortwave direct aerosol radiative forcing at the Gosan supersite, Korea during ACE-Asia, Atmos. Environ., 40, 6718-6729, 2006.

Kinne, S., Schulz, M., Textor, C., et al.: An AeroCom initial assessment-optical properties in aerosol component modules of global models, Atmos. Chem. Phys., 6, 1815-1834, 2006, http://www.atmos-chem-phys.net/6/1815/2006/.

Kinne, S., Lohmann, U., Feichter, J., Schulz, M., et al.: Monthly averages of aerosol properties: A global comparison among models, satellite data, and AERONET ground data, J. Geophys. Res., 108, 4634, doi:10.1029/2001JD001253, 2003.

Laurent, B., Marticorena, B., Bergametti, G., et al.: Simulation of the mineral dust emission frequencies from desert areas of China and Mongolia using an aerodynamic roughness length map derived from the POLDER/ADEOS 1 surface products, J. Geophys. Res., 110, D18S04, doi:10.1029/2004JD005013, 2005.

Laurent, B., Marticorena, B., Bergametti, G., and Mei, F.: Modeling mineral dust emissions from Chinese and Mongolian deserts, Global Planet. Change, 52, 121-141, 2006.

Luo, C., Mahowald, N. M., and del Corral, J.: Sensitivity study of meteorological parameters on mineral aerosol mobilization, transport, and distribution, J. Geophys. Res., 108(D15), 4447, doi: 10.1029/2003JD003483, 2003.

Marticorena, B. and Bergametti, G.: Modeling the atmospheric dust cycle: 1 . Design of a soil derived dust emission scheme, J. Geophys. Res., 100, 16415-16430, 1995.

Marticorena, B., Bergametti, G., Aumont, B., et al.: Modeling the atmospheric dust cycle: 2. Simulations of Saharan dust sources, J. Geophys. Res., 102, 4387-4404, 1997a.

Marticorena, B., Bergametti, G., Gillette, D. A., and Belnap, J.: Factors controlling threshold friction velocity in semiarid and arid areas of the United States, J. Geophys. Res., 102, $23277-$ $23287,1997 b$.

Marticorena, B., Chazette, P., Bergametti, G., Dulac, F., and Legrand, M.: Mapping the aerodynamic roughness length of desert surfaces from the POLDER/ADEOS bi-reflectance product, Int. J. Remote Sens., 25, 603-626, 2004.

Martin, J. H. and Fitzwater, S. E.: Iron deficiency limits phyto- 
plankton growth in the north-east Pacific subarctic, Nature, 331, 341-343, 1988.

Mei, F., Zhang, X., Lu, H., Shen, Z., and Wang, Y.: Characterization of MASDs of surface soils in north China and its influence on estimating dust emission, Chin. Sci. Bull., 49(20), 2169-2176, 2004.

Middleton, N. J.: A geography of dust storms in south-west Asia, J. Climatol., 6, 183-196, 1986.

Natsagdorj, L., Jugder, D., and Chung, Y. S.: Analysis of dust storms observed in Mongolia during 1937-1999, Atmos. Environ., 37, 1401-1411, 2003.

Petit, J. R., Jouzel, J., Mounier, L., Korotkevich, Y. S., Kotlyakov, V. I. and Lorius, C.: Palaeoclimatological and chronological implications of the Vostok core dust record, Nature, 343, 56-58, 1990.

Petit, J. R., Jouzel, J., Raynaud, D., et al.: Climate and atmospheric history of the past 420000 years from the Vostok ice core, Antarctica, Nature, 399, 429-436, 1999.

Prigent, C., Tegen, I., Aires, F., Marticorena, B., and Zribi, M.: Estimation of the aerodynamic roughness length in arid and semiarid regions over the globe with the ERS scatterometer, J. Geophys. Res., 110, D09205, doi:10.1029/2004JD005370, 2005.

Prospero, J. M.: Long-term measurements of the transport of African mineral dust to the southeastern United States: Implications for regional air quality, J. Geophys. Res., 104(D13), 15 917-15 927, 1999.

Shao, Y., Yang, Y., Wang, J., et al.: Northeast Asian dust storms: Real-time numerical prediction and validation, J. Geophys. Res., 108(D22), 4691, doi:10.1029/2003JD003667, 2003.

Sokolik, I. N. and Toon, O. B.: Direct radiative forcing by anthropogenic airborne mineral aerosols, Nature, 381, 681-683, 1996.

Solomon, P. A., Fall, T., Salmon, L., Cass, G. R., Gray, H. A., and Davision, A.: Chemical characteristics of PM10 aerosols collected in the Los Angeles Area, JAPCA, 39, 154-163, 1989.

Stier, P., Feichter, J., Kinne, S., et al.: The aerosol-climate model ECHAM5-HAM, Atmos. Chem. Phys., 5, 1125-1156, 2005, http://www.atmos-chem-phys.net/5/1125/2005/.

Sun, J.: Provenance of loess material and formation of loess deposits on the Chinese Loess Plateau, Earth Planet. Sci. Lett., 203, 845-859, 2002.

Tegen, I., Lacis, A. A., and Fung, I.: The influence on climate forcing of mineral aerosol from disturbed soils, Nature, 380, 419422, 1996.
Tegen, I., Harrison, S. P., Kohfeld, K., Prentice, I. C., Coe, M., and Heimann, M.: Impact of vegetation and preferential source areas on global dust aerosol: Results from a model study, J. Geophys. Res., 107(D21), 4576, doi:10.1029/2001JD000963, 2002.

Tegen., I., Werner, M., Harrison, S. P., and Kohfeld, K. E.: Relative importance of climate and land use in determining present and future global soil dust emission, Geophys. Res. Lett., 31, L05105, doi:10.0129/2003GL019216, 2004.

Timmreck, C. and Schulz, M.: Significant dust simulation differences in nudged and climatological operation mode of the AGCM ECHAM, J. Geophys. Res., 109, D13202, doi:10.1029/2003JD004381, 2004.

Van Den Hurk, B., Viterbo, P., Beljaars, A., and Betts, A.: Offline validation of the ERA40 surface scheme, ECMWF Tech Memo, 295, 42 pp., 2000.

Werner, M., Tegen, I., Harrison, S. P., et al.: Seasonal and interannual variability of the mineral dust cycle under present and glacial climate conditions, J. Geophys. Res., 107(D1), 4001, doi:10.1029/2002JD002365, 2002.

Xu, X., Levy, J. K., Lin, Z., and Chen, H.: An investigation of sanddust storm events and land surface characteristics in China using NOAA NDVI data, Global Planet. Change, 52, 182-196, 2006.

Yabuki, S., Mikami, M., Nakamura, Y., et al.: The characteristics of atmospheric aerosol at Aksu, an Asian dust-source region of North-West China: A summary of observations over the three years from March 2001 to April 2004, J. Meteorol. Soc. Jpn, 83A, 45-72, 2005.

Yang, G., Xiao, H., and Tuo, W.: Black windstorm in northwest China: a case study of the strong sand-dust storm on May 5th 1993, Global Alarm: Dust and Sandstorms from the World's Drylands, United Nations: Bangkok, Thailand, 49-73, 2001.

Zha, Y. and Gao, J.: Characteristics of desertification and its rehabilitation in China, J. Arid Environ., 37, 419-432, 1997.

Zhang, X. Y., Gong, S. L., Shen, Z. X., et al.: Characterization of soil dust aerosol in China and its transport and distribution during 2001 ACE-Asia: 1. Network observations, J. Geophys. Res. 108(D9), 4261, doi:10.1029/2002JD002632, 2003.

Zobler, L.: A world soil file for global climate modeling, NASA Tech. Memo, 87802, 32 pp., 1986. 